\title{
FORUM
}

\section{Rhumb-line and Great-circle Sailings}

\author{
M. R. H. Llewellyn
}

A STUDENT of navigation who refers to the standard textbooks will be confronted with a multiplicity of sailings which are said to include plane sailing, parallel sailing, middle or mid-latitude sailing, mean latitude sailing, traverse sailing, short distance sailing using rhumb-line formulae, mercator sailing, great-circle sailing, approximate great-circle sailing, composite sailing and composite greatcircle sailing. To the student it may seem a reasonable assumption that so many differently named sailings are based upon as many different ways of taking a ship from one position to another, which is of course a nonsense.

The problem to be solved by any method of sailing is that of relating a ship's movement across the Earth's surface, defined by course and distance travelled in nautical miles, to corresponding changes of coordinates of position in terms of latitude and longitude; or alternatively, that of relating desired changes of coordinates into a corresponding movement across the Earth's surface. A ship moving across an ocean must follow a curved path because she is moving across the surface of an approximately spheroidal Earth. In practice this path will take the form of either a rhumb line or of a series of short rhumb lines which will approximate to a great circle. The former offers the advantage of steering a constant course at the cost of greater distance, whilst the latter offers a shorter distance at the cost of making some determined number of alterations to the course angle. It would therefore follow that in principle there are only two distinct methods of sailing, namely rhumb-line sailing and (approximate) great-circle sailing.

Rhumb-line sailing first requires a definition of what is meant by a rhumb line and this may be taken as being 'a line on the Earth's surface which cuts all the meridians at the same angle' (Admiralty Manual of Navigation, Vol. II). In general rhumb lines cut the meridians obliquely and spiral towards the nearer pole as loxodromes; however, there are special cases where a rhumb line coincides with a parallel of latitude (a small circle) or with the equator (a great circle) and it would be pedantic not to include as a rhumb line a line which coincided with a meridian (again a great circle). Rhumb-line sailing therefore comprises:

(i) Sailing along a parallel, course angle $090^{\circ}$ or $270^{\circ}$. No change of latitude is involved and the problem is that of converting distance in nautical miles run along the parallel (departure) into a corresponding change of longitude for that particular latitude. The approximate formula : Difference of longitude $=$ departure $\times$ secant latitude, may be derived.

(ii) Sailing along the equator, course angle $090^{\circ}$ or $270^{\circ}$. No change of latitude; distance run may be considered as being the corresponding change of longitude measured in minutes of arc. 
(iii) Sailing along a meridian, course angle $000^{\circ}$ or $180^{\circ}$. No change of longitude; distance run may be taken as being the corresponding change of latitude in minutes of arc.

(iv) Sailing along any other rhumb line, i.e. along a loxodrome. This will involve changes of both latitude and longitude. It may be shown by summation that difference of latitude $=$ rhumb-line distance $\times$ cosine course angle.

The problem of finding the corresponding change of longitude may be solved in one of two ways:

(a) It may be shown that over short distances, i.e. in practice any distance less than a normal day's run for ships of speeds up to about twenty knots, the approximate formula, difference of longitude $=$ rhumb-line distance $\times$ sine course angle $x$ secant mean latitude is valid, where the departure and arrival positions lie in the same hemisphere and the mean latitude is the arithmetic mean of the two latitudes concerned.

(b) Over longer distances it may be shown that difference of longitude = difference of meridional parts $\times$ tangent course angle. An explanation of the relationship between longitude units and meridional parts should be given when discussing the mercator equatorial projection which might usefully precede a discussion of the sailings.

(Approximate) great-circle sailing, based on the assumption of a spherical Earth, is a straightforward concept which requires the solution of a spherical triangle using the haversine formula or short method tables. Suitable positions are determined along the great-circle track and rhumb lines between these positions are calculated. The consecutive rhumb lines will approximate to the great-circle track.

Composite sailing, as its name implies, involves the use of a composite track. An initial great circle, which at its vertex meets some limiting parallel of latitude, is followed by a rhumb line along the parallel to the vertex of a final great circle which takes the ship to its destination.

It is submitted that this or some similar treatment of the sailings which refers only to rhumb-line sailing, (approximate) great-circle sailing and composite sailing is logical in its approach and relates the sailings to what is current practice at sea. It must be conceded that in this discussion the Earth has been variously and inconsistently treated as either a sphere or a spheroid, when it is in fact neither. In defence it may be said that the discussion concerns the proposed rationalization of practical navigation as at present taught and practised. The inconsistencies and approximations may require explanation to enquiring minds but unsought explanation might serve only to confuse the less able student. Practical navigation is seldom scientifically precise and a more sophisticated study of the subject may be left to a later stage of the student's academic training. 